\title{
Clinical value of fluorine-18a- methyltyrosine PET in patients with gliomas: comparison with fluorine-18 fluorodeoxyglucose PET
}

Keishi Horiguchi ${ }^{1 *}$, Masahiko Tosaka' ${ }^{1}$, Tetsuya Higuchi ${ }^{2}$, Yukiko Arisaka², Kenichi Sugawara ${ }^{1}$, Junko Hirato ${ }^{4}$, Hideaki Yokoo ${ }^{3}$, Yoshito Tsushima² and Yuhei Yoshimoto ${ }^{1}$

\begin{abstract}
Background: We investigated the relationship between metabolic activity and histological features of gliomas using fluorine-18a-methyltyrosine $\left({ }^{18} \mathrm{~F}-\mathrm{FAMT}\right)$ positron emission tomography (PET) compared with fluorine-18 fluorodeoxyglucose $\left({ }^{18} \mathrm{~F}-\mathrm{FDG}\right)$ PET in 38 consecutive glioma patients. The tumor to normal brain ratios ( $\mathrm{T} / \mathrm{N}$ ratios) were calculated, and the relationships between $\mathrm{T} / \mathrm{N}$ ratio and World Health Organization tumor grade or MIB-1 labeling index were evaluated. The diagnostic values of T/N ratios were assessed using receiver operating characteristic (ROC) curve analyses to differentiate between high-grade gliomas (HGGs) and low-grade gliomas (LGGs).

Results: Median T/N ratio of ${ }^{18}$ F-FAMT PET was 2.85, 4.65, and 4.09 for grade II, III, and IV gliomas, respectively, with significant differences between HGGs and LGGs $(p=0.006)$. Both T/N ratio $(p=0.016)$ and maximum standardized uptake value ( $p=0.033$ ) of ${ }^{18}$ F-FDG PET showed significant differences between HGGs and LGGs. ROC analysis yielded an optimal cut-off of 3.37 for the T/N ratio of ${ }^{18} \mathrm{~F}$-FAMT PET to differentiate between HGGs and LGGs (sensitivity $81 \%$, specificity $67 \%$, accuracy $76 \%$, area under the ROC curve 0.776 ). Positive predictive value was $84 \%$, and negative predictive value was $62 \%$. T/N ratio of ${ }^{18} \mathrm{~F}$-FAMT PET was not correlated with MIB-1 labeling index in all gliomas, whereas T/N ratio of ${ }^{18} \mathrm{~F}-\mathrm{FDG}$ PET was positively correlated $\left(r_{s}=0.400, p=0.013\right)$. Significant positive correlation was observed between T/N ratios of ${ }^{18} \mathrm{~F}-\mathrm{FDG}$ and ${ }^{18} \mathrm{~F}-\mathrm{FAMT}\left(r_{s}=0.454, p=0.004\right)$, but median T/N ratio of ${ }^{18}$ F-FAMT PET was significantly higher than that of ${ }^{18} \mathrm{~F}$-FDG PET in all grades of glioma.

Conclusions: The T/N ratio of ${ }^{18} \mathrm{~F}$-FAMT uptake has high positive predictive value for detection of HGGs. ${ }^{18} \mathrm{~F}$-FAMT PET had higher T/N ratio, with better tumor-normal brain contrast, compared to ${ }^{18} \mathrm{~F}$-FDG PET in both LGGs and HGGs. Therefore, ${ }^{18} \mathrm{~F}$-FAMT is a useful radiotracer for the preoperative visualization of gliomas.
\end{abstract}

Keywords: ${ }^{18}$ F-FAMT, PET, Glioma, ${ }^{18}$ F-FDG, MIB-1 labeling index

\footnotetext{
* Correspondence: keishi6364ns@mac.com

${ }^{1}$ Department of Neurosurgery, Gunma University Graduate School of

Medicine, 3-39-22 Showa-machi, Maebashi, Gunma 371-8511, Japan

Full list of author information is available at the end of the article
} 


\section{Background}

Magnetic resonance imaging with or without gadolinium enhancement is the standard method for the diagnosis of brain tumors, but new imaging methods have also been proposed based on the specific metabolic characteristics of gliomas. Malignant gliomas have increased metabolism caused by anaerobic glycolysis, so that positron emission tomography (PET) using fluorine-18 fluorodeoxyglucose $\left({ }^{18} \mathrm{~F}\right.$-FDG), a glucose analog, is now widely used for the diagnosis of gliomas [1]. However, the high utilization of glucose by normal gray matter makes identification of other brain tumors difficult on ${ }^{18}$ F-FDG PET [2]. Consequently, PET imaging of glucose metabolism is basically unsuitable for the detection of tumors against the background of the normal brain.

Radiolabeled amino acids are well-established tracers for brain tumor imaging with PET. The Response Assessment in Neuro-Oncology working group has recently recommended the use of amino acid PET imaging for brain tumor management in addition to magnetic resonance imaging [3, 4]. L-[methyl- $\left.{ }^{11} \mathrm{C}\right]$ methionine $\left({ }^{11} \mathrm{C}-\mathrm{MET}\right)$ is the most widely used amino acid PET imaging tracer for gliomas for the preoperative detection, diagnosis of subtypes and grades, differential diagnosis from radiation necrosis, estimation of tumor infiltration, and delineation of the border of tumor removal $[5,6]$. Methyl- ${ }^{11} \mathrm{C}$-choline, another PET radiotracer, potentially reflects the grade of malignancy [7]. However, the short half-life $(20 \mathrm{~min})$ of ${ }^{11} \mathrm{C}$ requires in-house radiosynthesis and repeated radiolabeling of the tracer for each PET study, resulting in limited use only in PET centers with an in-house cyclotron facility [7]. Consequently, development of an amino acid tracer using the long half-life of ${ }^{18} \mathrm{~F}$ has been desirable to overcome these disadvantages of ${ }^{11} \mathrm{C}$-labeled agents [2]. Recently, the ${ }^{18} \mathrm{~F}$-based PET tracers, $\mathrm{O}-\left(2-\left[{ }^{18} \mathrm{~F}\right]\right.$ fluoroethyl)L-tyrosine $\left({ }^{18} \mathrm{~F}\right.$-FET) and L-6- $\left[{ }^{18} \mathrm{~F}\right]$ fluoro-3,4-dihydroxyphenylalnine have been used for the imaging of brain tumors [8-12]. In Europe, the high clinical interest in ${ }^{18}$ F-FET PET has led to more than 10000 PET scans being performed in some centers [13].

Previously, we developed L- $\left[3-{ }^{18} \mathrm{~F}\right]-\alpha$-methyltyrosine $\left({ }^{18}\right.$ F-FAMT), a new amino acid tracer for PET imaging and demonstrated its potential for detecting neoplasms using experimental tumor models $[14,15] .{ }^{18}$ F-FAMT accumulates in tumor cells only via an amino acid transport system, and most of the incorporated ${ }^{18} \mathrm{~F}$-FAMT is not metabolized [14, 15]. Recently, we have made advances in the clinical utility of ${ }^{18}$ F-FAMT PET for the investigation of lung cancers, oral and maxillofacial cancers, and other tumors [16-20]. Our preliminary study showed specific accumulation of the tracer in 15 patients with glioma, including 7 cases before treatment [21]. However, no detailed study has assessed ${ }^{18}$ F-FAMT PET in a glioma series.
The present study investigated the value of ${ }^{18} \mathrm{~F}$-FAMT uptake for differentiating high-grade glioma (HGG) from low-grade glioma (LGG) and the correlation with the proliferation rate, compared with ${ }^{18}$ F-FDG as the standard PET tracer.

\section{Methods \\ Patients}

The clinical records of patients treated between July 2007 and December 2013 were retrospectively reviewed. The criteria for inclusion were (i) histopathology of the tumor was established by open surgery or by stereotactic biopsy, and (ii) both ${ }^{18}$ F-FAMT PET and ${ }^{18}$ F-FDG PET were performed in random order before surgery within 2 months. The histological type of the tumors was determined by the World Health Organization (WHO) classification system [22]. No cases of pilocytic astrocytomas (WHO grade I) were included. Extremely rare histological types were also excluded. None of the patients had insulin-dependent diabetes, and serum glucose levels were less than $120 \mathrm{mg} / \mathrm{dL}$ in all patients just before ${ }^{18}$ F-FAMT or ${ }^{18}$ F-FDG injection. All patients agreed to participate in this study and provided written informed consent. This study was approved by the institutional review board of Gunma University Graduate School of Medicine.

\section{PET studies}

Both ${ }^{18}$ F-FDG and ${ }^{18}$ F-FAMT were synthesized in the cyclotron facility of our institute, with ${ }^{18} \mathrm{~F}$-FAMT produced according to the methods of Tomiyoshi et al. [14].

In this study, PET used a Discovery STE (GE Healthcare, Waukesha, WI, USA) or Biograph 16 (Siemens Medical Solutions, Knoxville, TN, USA) scanner, with field of view of $700 \mathrm{~mm}$ and slice thickness of $3.27 \mathrm{~mm}$. Three-dimensional data acquisition was performed for 3 min per bed position, followed by imaging reconstruction with the three-dimensional ordered-subset expectation maximization method. Correction of segmented attenuation was based on $128 \times 128$ matrix images obtained by X-ray computed tomography (CT) (140 kV, 120-240 mAs) without intravenous contrast material. CT images were reconstructed using a conventional filtered back projection method. Axial fullwidth half-maximum at $1 \mathrm{~cm}$ from the center of field of view was $5.6 \mathrm{~mm}$, and $\mathrm{z}$-axis full-width halfmaximum at $1 \mathrm{~cm}$ from the center of field of view was $6.3 \mathrm{~mm}$. Intrinsic system sensitivity was $8.5 \mathrm{cps} / \mathrm{kBq}$ for three-dimensional acquisition. Patients were scanned from the thigh to the head in the arms-down position. Limited breath-holding at normal expiration was used during $\mathrm{CT}$ to avoid motion-induced artifacts and allow co-registration of CT and PET images in the area of the diaphragm. 


\section{Imaging analysis}

All ${ }^{18}$ F-FAMT PET and ${ }^{18}$ F-FDG PET images were interpreted by two independent experienced nuclear physicians (Y.A. and T.H.), and final values were determined by consensus. Spearman's correlation coefficient was used to evaluate the interrater reliability. The interpreting physicians were unaware of the patient's clinical history and data. For semi-quantitative analysis, the standardized uptake value (SUV) was obtained from an attenuation-corrected transaxial image. SUV was calculated as follows: radioactive concentration in the region of interest (ROI) $(\mathrm{MBq} / \mathrm{g}) /$ injected dose $(\mathrm{MBq}) /$ patient body weight $(\mathrm{g})$. The ROI was manually drawn over the primary tumor. ROI analysis was conducted by a nuclear medicine physician with reference to the $\mathrm{CT}$ and magnetic resonance images. The maximum SUV $\left(\mathrm{SUV}_{\max }\right)$ and mean SUV in the ROI represent the uptake of ${ }^{18} \mathrm{~F}$ FAMT and ${ }^{18} \mathrm{~F}$-FDG in the lesion [23]. The ratio of the $\mathrm{SUV}_{\text {max }}$ in the tumor to the mean SUV in the contralateral normal brain ( $\mathrm{T} / \mathrm{N}$ ratio) was calculated. If the lesion was located in the thalamus, the $\mathrm{T} / \mathrm{N}$ ratio to the contralateral normal thalamus was calculated.

\section{Histological study}

Surgical or biopsy specimens were fixed in $10 \%$ formalin and were embedded in paraffin. The histological tumor type was established based on specimens stained with hematoxylin and eosin, according to the previous WHO criteria [22]. The relevance of this investigation is limited by the fact that the tumor classification is based on the previous, out-of-date WHO classification and so may no longer be directly applicable to the current classification [24].

The cellular proliferation activity of the tumor was determined by measuring the MIB-1 proliferation index obtained by immunohistochemical staining with anti-Ki67/MIB-1 antibody (Dako, Tokyo, Japan). The percentage of tumor cells stained positively for MIB-1 antigen (MIB-1 labeling index: MIB-1 LI) was determined in the area containing the largest number of positive tumor cells and was regarded as representative of the tumor proliferation activity.

\section{Statistical analysis}

All values are reported as proportions (\%) or medians with interquartile range. Between-group comparisons of non-parametric data were performed using the MannWhitney $U$ test. To compare $\mathrm{T} / \mathrm{N}$ ratios between ${ }^{18} \mathrm{~F}$ FAMT and ${ }^{18} \mathrm{~F}$-FDG, the Wilcoxon's signed-rank test was used because of matched pairing. The correlation between different variables was analyzed using the non-parametric Spearman's rank test. Probability values of $<0.05$ indicated a statistically significant difference. The diagnostic accuracy of the $\mathrm{T} / \mathrm{N}$ ratio and $S U V_{\max }$ of ${ }^{18}$ F-FAMT and ${ }^{18}$ F-FDG uptake for differentiation of HGGs from LGGs was evaluated by receiver-operatingcharacteristic (ROC) curve analysis using subsequent histological analysis of all lesions. The decision cutoff was considered optimal at the maximum of the product of paired values for sensitivity and specificity. In addition, the area under the ROC curve (AUC), its median, and the level of significance were determined as measures of the diagnostic quality of the test. For ROC analysis, the gliomas of WHO grades III and IV were considered together as HGGs. Statistical analysis was performed using SPSS version 21 (IBM Corp., Armonk, NY, USA) for Mac.

\section{Results}

\section{Uptake of ${ }^{18}$ F-FAMT and ${ }^{18} \mathrm{~F}$-FDG}

This study included 38 patients (24 men and 14 women), aged 16 to 79 years (median 52.5 years). The final pathological diagnosis was based on samples obtained by open craniotomy $(n=37)$ or biopsy $(n=1)$. The tumors were classified as WHO grade II in 12 patients, grade III in 12 , and grade IV in 14, and the histological diagnoses are summarized in Table 1. The median SUV in the contralateral normal cortex was 0.94 (range 0.49 to 1.50) for ${ }^{18}$ F-FAMT, and 5.91 (range 2.20-18.9) for ${ }^{18}$ F-FDG. The $\mathrm{SUV}_{\max }$ and $\mathrm{T} / \mathrm{N}$ ratio of ${ }^{18} \mathrm{~F}$-FAMT and ${ }^{18} \mathrm{~F}$-FDG are summarized in Table 2. Correlation coefficient and interobserver agreement for quantitative measurements was very high in all cases $(p<0.01)$.

\section{$\mathrm{T} / \mathrm{N}$ ratio and $\mathrm{SUV}_{\max }$}

The median $\mathrm{T} / \mathrm{N}$ ratio of ${ }^{18} \mathrm{~F}$-FAMT PET was $2.85,4.65$, and 4.09 for grades II, III, and IV in all gliomas, respectively (Table 2 ). The median $\mathrm{T} / \mathrm{N}$ ratio of ${ }^{18} \mathrm{~F}$-FAMT PET was 2.85 for LGGs and 4.37 for HGGs, showing a significant difference between LGGs and HGGs $(p=0.006$, Fig. 1a). The median $S V_{\max }$ of ${ }^{18}$ F-FAMT PET was

Table 1 Histological characteristics of the tumors

\begin{tabular}{lll}
\hline Histopathology & $n(\%)$ & Median MIB-1 LI (IQR) \\
\hline WHO grade II & $12(32)$ & $4.1(2.9-7.6)$ \\
Diffuse astrocytoma & $3(8)$ & 7.4 \\
Oligoastrocytoma & $7(18)$ & $3.8(2.7-4.4)$ \\
Oligodendroglioma & $2(5)$ & 5.3 \\
WHO grade III & $12(32)$ & $16(12-27)$ \\
Anaplastic astrocytoma & $3(8)$ & 30 \\
Anaplastic oligoastrocytoma & $5(13)$ & $14(9-21)$ \\
Anaplastic oligodendroglioma & $4(11)$ & $16(7.7-19)$ \\
WHO grade IV & $14(37)$ & $28(21-41)$ \\
Glioblastoma & $14(37)$ & $28(21-41)$
\end{tabular}

MIB-1 LI MIB-1 labeling index, IQR interquartile range 
Table $2{ }^{18}$ F-FAMT and ${ }^{18} \mathrm{~F}$-FDG uptake in various tumor types

\begin{tabular}{|c|c|c|c|c|}
\hline \multirow[t]{2}{*}{ Histological classification } & \multicolumn{2}{|l|}{${ }^{18}$ F-FAMT } & \multicolumn{2}{|l|}{${ }^{18} \mathrm{~F}-\mathrm{FDG}$} \\
\hline & Median SUV $\max (I Q R)$ & Median T/N ratio (IQR) & Median SUV $\max (\mathrm{IQR})$ & Median T/N ratio (IQR) \\
\hline All gliomas & $3.45(2.58-4.63)$ & $4.08(2.87-4.76)$ & $6.65(5.55-10.2)$ & $1.12(0.86-1.83)$ \\
\hline WHO grade II & $2.88(2.04-3.75)$ & $2.85(2.06-4.28)$ & $5.40(4.20-8.45)$ & $0.88(0.75-1.04)$ \\
\hline Diffuse astrocytoma & 3.07 & 2.05 & 4.10 & 0.90 \\
\hline Oligoastrocytoma & $2.65(1.90-4.00)$ & $2.80(2.11-4.33)$ & $5.10(4.50-5.80)$ & $0.86(0.62-0.88)$ \\
\hline Oligodendroglioma & 3.60 & 4.23 & 10.7 & 1.39 \\
\hline WHO grade III & $4.20(2.17-5.75)$ & $4.65(3.50-5.42)$ & $6.55(6.00-8.28)$ & $1.17(0.68-2.24)$ \\
\hline Anaplastic astrocytoma & 2.63 & 5.20 & 6.60 & 1.22 \\
\hline Anaplastic oligoastrocytoma & $2.68(1.61-5.15)$ & $4.29(2.47-5.05)$ & $6.00(4.93-6.45)$ & $0.71(0.63-1.17)$ \\
\hline Anaplastic oligodendroglioma & $5.70(4.93-6.40)$ & $5.03(3.71-6.39)$ & $12.8(6.70-21.3)$ & $1.91(1.17-2.75)$ \\
\hline WHO grade IV & $3.60(3.05-4.60)$ & $4.09(3.36-4.92)$ & $9.15(6.38-11.5)$ & $1.56(1.11-2.50)$ \\
\hline Glioblastoma & $3.60(3.05-4.60)$ & $4.09(3.36-4.92)$ & $9.15(6.38-11.5)$ & $1.56(1.11-2.50)$ \\
\hline
\end{tabular}

IQR interquartile range

$2.88,4.20$, and 3.60 for grade II, III, and IV gliomas, respectively. However, the $\mathrm{SUV}_{\max }$ of ${ }^{18} \mathrm{~F}$-FAMT PET showed no significant differences between LGGs and HGGs ( $p=0.087$, Fig. 1b).

The median $\mathrm{T} / \mathrm{N}$ ratio of ${ }^{18} \mathrm{~F}$-FDG PET was $0.88,1.17$, and 1.56 for grade II, III, and IV gliomas, respectively (Table 2). The median $\mathrm{T} / \mathrm{N}$ ratio of ${ }^{18} \mathrm{~F}-\mathrm{FDG}$ PET was
0.88 for LGGs and 1.27 for HGGs. The median SUV $\max$ of ${ }^{18}$ F-FDG PET was 5.40, 6.55, and 9.15 for grade II, III, and IV gliomas, respectively. The median $\mathrm{SUV}_{\max }$ of ${ }^{18}$ F-FDG PET was 5.40 for LGGs and 7.37 for HGGs. Both the $\mathrm{T} / \mathrm{N}$ ratio and the $\mathrm{SUV}_{\max }$ of ${ }^{18} \mathrm{~F}$-FDG PET showed significant differences between HGGs and LGGs $(p=0.016$ and $p=0.033$, respectively, Fig. $1 \mathrm{c}, \mathrm{d})$.
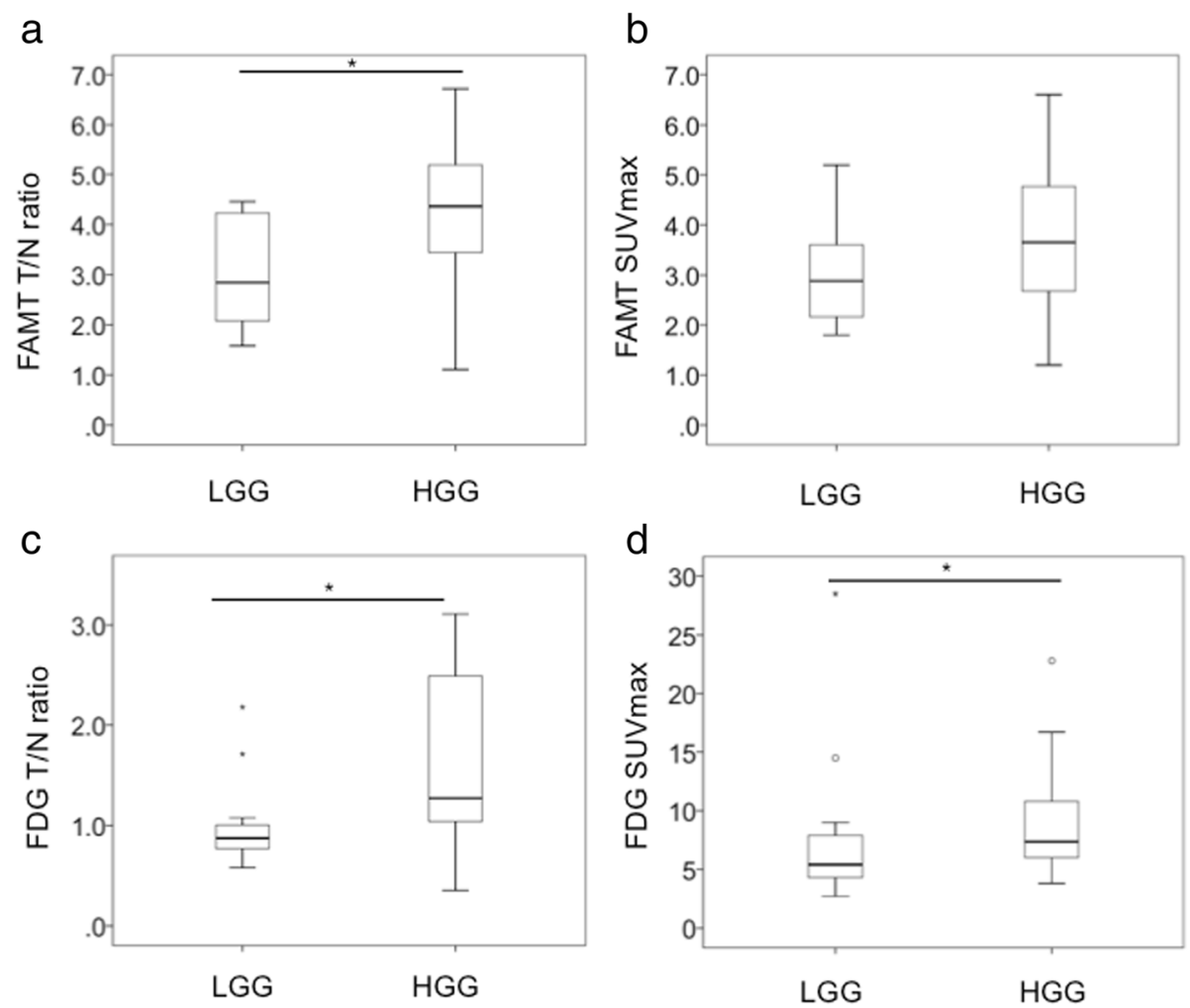

Fig. 1 Box-and-whisker plots of ${ }^{18} \mathrm{~F}$-FAMT and ${ }^{8} \mathrm{~F}$-FDG uptake for LGG and HGG. a The difference in T/N ratio of ${ }^{18} \mathrm{~F}$-FAMT uptake between LGG and HGG was significant $(p=0.006)$. b The difference in SUV $\max$ of ${ }^{18}$ F-FAMT uptake between LGG and HGG was not significant $(p=0.087)$. $\mathbf{c}, \mathbf{d}$ The differences in T/N ratio and SUV $\max$ of ${ }^{18} \mathrm{~F}$-FDG uptake between LGG and HGG were significant $(p=0.016$ and $p=0.033$, respectively) 
ROC analysis for ${ }^{18}$ F-FAMT PET and ${ }^{18}$ F-FDG PET

$\mathrm{T} / \mathrm{N}$ ratio of ${ }^{18} \mathrm{~F}$-FAMT PET was significantly higher for HGGs $(n=26)$ than for LGGs $(n=12)(4.37 \pm 2.22$ vs. 2.85 $\pm 1.81 ; p=0.006$ ) (Fig. 1a). ROC analysis for differentiation between HGGs and LGGs yielded an optimal cutoff of 3.37 for the $\mathrm{T} / \mathrm{N}$ ratio (sensitivity $81 \%$, specificity $67 \%$, accuracy $76 \%$, AUC 0.776, 95\% confidence interval [CI] 0.623-0.928). The positive predictive value (PPV) was $84 \%$, and the negative predictive value (NPV) was $62 \%$ (Fig. 2). On the other hand, the $\mathrm{SUV}_{\max }$ of ${ }^{18} \mathrm{~F}$-FAMT PET showed no significant differences between HGGs and LGGs $(3.65 \pm 2.16$ vs. 2.88 \pm 1.71 ; $p=0.087$ ) (Fig. 1b). ROC analysis for differentiation between HGGs and LGGs yielded an optimal cutoff of 3.45 for $\mathrm{SUV}_{\max }$ of ${ }^{18}$ F-FAMT PET (sensitivity $61.5 \%$, specificity $75 \%$, accuracy $66 \%$, AUC $0.675,95 \%$ CI $0.497-0.852$ ). The PPV was $84 \%$, and the NPV was $47 \%$ (Fig. 2).

$\mathrm{T} / \mathrm{N}$ ratio of ${ }^{18} \mathrm{~F}$-FDG PET was significantly higher for HGGs than for LGGs $(1.27 \pm 1.47$ vs. $0.88 \pm 0.29 ; p=$ 0.016) (Fig. 1c). ROC analysis yielded an optimal cutoff of 0.92 for the $\mathrm{T} / \mathrm{N}$ ratio of ${ }^{18} \mathrm{~F}$-FDG PET to differentiate between HGGs and LGGs (sensitivity $81 \%$, specificity $67 \%$, accuracy $76 \%$, AUC 0.742 , 95\% CI 0.575-0.909). The PPV was $84 \%$, and the NPV was $62 \%$ (Fig. 2). Similarly, $\mathrm{SUV}_{\max }$ of ${ }^{18} \mathrm{~F}$-FDG PET was significantly higher for HGGs than for LGGs ( $7.37 \pm 4.92$ vs. $5.40 \pm 4.25 ; p=0.033$ ) (Fig. 1d). ROC analysis for differentiation between HGGs and LGGs yielded an optimal cutoff of 5.85 for $\mathrm{SUV}_{\max }$ of ${ }^{18}$ F-FDG PET (sensitivity $89 \%$, specificity $67 \%$, accuracy 82 , AUC 0.716 , 95\% CI $0.510-0.923)$. The PPV was $85 \%$, and the NPV was 73\% (Fig. 2).

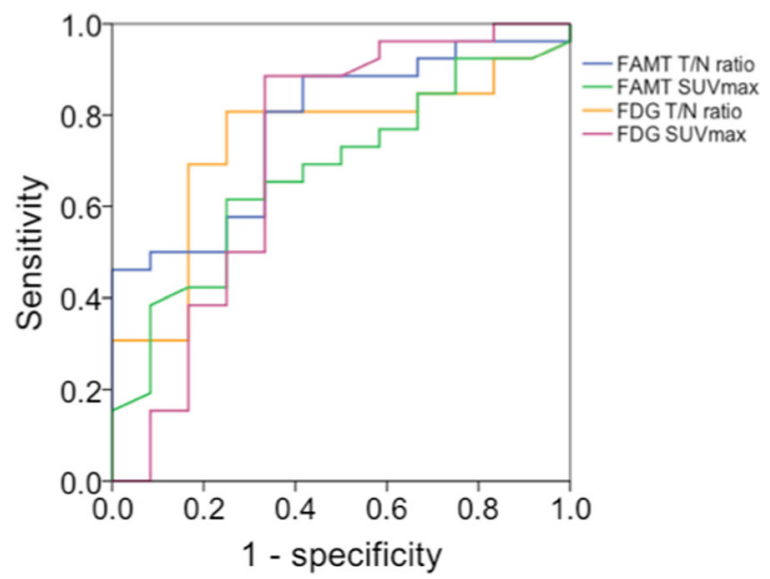

Fig. 2 ROC curve analysis of T/N ratio (blue curve) and SUV max (green curve) of ${ }^{8} \mathrm{~F}$-FAMT to differentiate between HGGs and LGGs. Area under the curve was 0.776 for T/N ratio ( $p=0.007$, 95\% Cl $0.623-$ 0.928 , optimal cutoff 3.37) and 0.675 for $\operatorname{SUV}_{\max }(p=0.087,95 \% \mathrm{Cl}$ 0.497-0.852, optimal cutoff 3.45). ROC curve analysis of T/N ratio

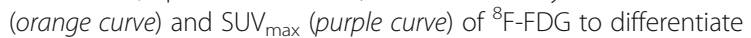
between HGGs and LGGs. Area under the curve was 0.742 for T/N ratio ( $p=0.018,95 \% \mathrm{Cl} 0.575-0.909$, optimal cutoff 0.92$)$ and 0.716 for $\operatorname{SUV}_{\max }(p=0.034,95 \%$ Cl 0.510-0.923, optimal cutoff 5.85)

\section{MIB-1 LI and T/N ratio}

Neither the $\mathrm{SUV}_{\max }$ nor the $\mathrm{T} / \mathrm{N}$ ratio of ${ }^{18} \mathrm{~F}$-FAMT PET was correlated with the MIB-1 LI in all gliomas $\left(\mathrm{SUV}_{\text {max }}: r_{s}=0.138, p=0.408\right.$; T/N ratio: $r_{s}=0.290, p=$ 0.077; Fig. 3a). The T/N ratio of ${ }^{18} \mathrm{~F}-\mathrm{FDG}$ PET was also positively correlated with the MIB-1 LI in all gliomas $\left(r_{s}=\right.$ $0.400, p=0.013$; Fig. 3b), whereas the $\mathrm{SUV}_{\max }$ of ${ }^{18} \mathrm{~F}$-FDG PET was not correlated $\left(r_{s}=0.242, p=0.144\right)$.

\section{Comparison of ${ }^{18}$ F-FAMT and ${ }^{18} \mathrm{~F}$-FDG}

Significant positive correlation was observed between the $\mathrm{T} / \mathrm{N}$ ratios of ${ }^{18} \mathrm{~F}$-FDG and ${ }^{18} \mathrm{~F}$-FAMT in all gliomas $\left(r_{s}=0.454, p=0.004\right.$; Fig. $\left.4 \mathrm{a}\right)$. The median $\mathrm{T} / \mathrm{N}$ ratio of ${ }^{18}$ F-FAMT was significantly higher than that of ${ }^{18}$ F-FDG in all gliomas $(p<0.05$; Fig. $4 \mathrm{~b})$. The $\mathrm{T} / \mathrm{N}$ ratio of ${ }^{18} \mathrm{~F}$ FDG was lower than 1.0 in $15(39 \%)$ of 38 gliomas, resulting in poor tumor-normal brain contrast. On the other hand, the $\mathrm{T} / \mathrm{N}$ ratio of ${ }^{18} \mathrm{~F}$-FAMT was greater than 2.0 in 36 (95\%) of 38 gliomas, and all cases showed clear tumor-normal brain contrast. These results indicated that ${ }^{18} \mathrm{~F}$-FAMT provides better tumor-normal brain contrast. Representative cases are shown in Fig. 5.

\section{Discussion}

The $\mathrm{T} / \mathrm{N}$ ratios of both ${ }^{18} \mathrm{~F}$-FAMT and ${ }^{18} \mathrm{~F}$-FDG were significantly higher for HGGs than for LGGs, although the $\mathrm{T} / \mathrm{N}$ ratios of different tumor grades showed wide overlap. For HGGs, ${ }^{18}$ F-FAMT uptake beyond a T/N ratio cutoff of 3.37 or ${ }^{18} \mathrm{~F}$-FDG uptake beyond a $\mathrm{T} / \mathrm{N}$ ratio cutoff of 0.92 had a PPV of 84 or $84 \%$, respectively. The $\mathrm{T} / \mathrm{N}$ ratios of ${ }^{18} \mathrm{~F}$-FAMT were not correlated with MIB$1 \mathrm{LI}$ in all gliomas. The T/N ratio of ${ }^{18}$ F-FAMT was significantly higher than that of ${ }^{18} \mathrm{~F}$-FDG in all gliomas and all tumor subtypes.

Radiosynthesis of ${ }^{18}$ F-FAMT, an amino acid analog with a relatively high chemical yield, was originally developed at our institute [14], and experimental and clinical investigations have demonstrated that accumulation of ${ }^{18} \mathrm{~F}$-FAMT in tumor cells occurs via an amino acid transport system $[14,15,23] .{ }^{18}$ F-FAMT was predicted to act as a specific radiotracer of brain tumor tissue based on the low uptake by normal brain tissue compared with ${ }^{18} \mathrm{~F}$-FDG and has proven specificity to detect gliomas [15]. No significant relationship between ${ }^{18} \mathrm{~F}$ FAMT uptake and WHO grade of tumor was found in the first series of 15 glioma cases [21]. The current study has now demonstrated significantly different ${ }^{18}$ F-FAMT uptake in gliomas of various histologies and grades compared to ${ }^{18} \mathrm{~F}$-FDG.

Recently, ${ }^{11} \mathrm{C}$-MET PET has become the most commonly used amino acid imaging modality for gliomas, although use is restricted to PET centers with an in-house cyclotron facility. ${ }^{11} \mathrm{C}$-MET PET is useful for detecting and delineating gliomas [5, 6, 25-28]. ${ }^{11} \mathrm{C}$-MET uptake 
a

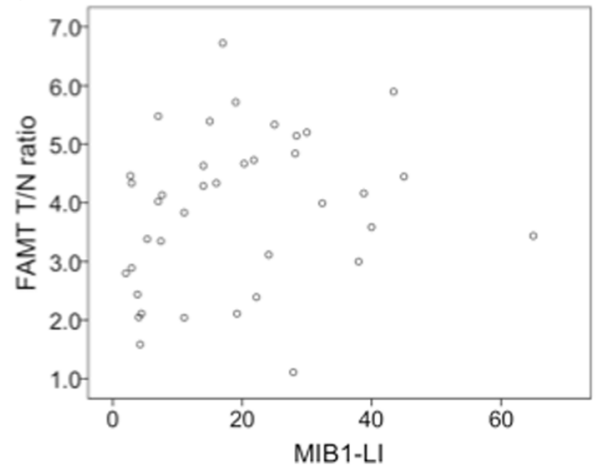

b

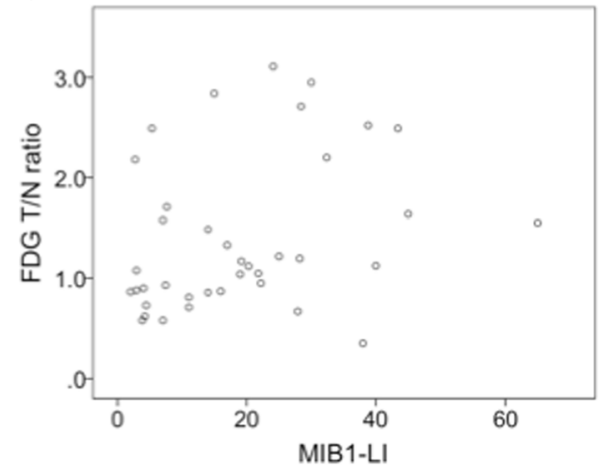

Fig. 3 Correlation analysis between the MIB-1 LI and the T/N ratio of ${ }^{18} \mathrm{~F}$-FAMT PET or ${ }^{18} \mathrm{~F}$-FDG PET. a The T/N ratio of ${ }^{18} \mathrm{~F}-\mathrm{FAMT}$ PET was not correlated with MIB-1 LI in all gliomas $\left(r_{s}=0.290, p=0.077\right)$. b The T/N ratio of ${ }^{18} \mathrm{~F}-\mathrm{FDG}$ PET was positively correlated with MIB-1 LI in all gliomas $\left(r_{5}=0.400, p=0.013\right)$

shows positive correlation with astrocytoma grade (II/IV and III/IV) [5, 27]. However, oligodendroglioma, which is a low-grade tumor, may show higher uptake of ${ }^{11} \mathrm{C}-\mathrm{MET}$ than diffuse astrocytoma (WHO grade II) [5]. ${ }^{18}$ F-FAMT tracer was developed on the basis of the known accumulation in brain tumor tissue of L-3-[ $\left.{ }^{123} \mathrm{I}\right]$ iodo- $\alpha$-methyl tyrosine [21]. Uptake of L-3-[ $\left.{ }^{123} \mathrm{I}\right]$ iodo- $\alpha$-methyl tyrosine and of ${ }^{11} \mathrm{C}$-MET involves almost the same transport mechanism, system $\mathrm{L}$, which is a $\mathrm{Na}$-independent amino acid transport system, in cultured glioma cell lines [29]. In fact, L-3- $\left[{ }^{123} \mathrm{I}\right]$ iodo- $\alpha$-methyl tyrosine single photon emission computed tomography and ${ }^{11} \mathrm{C}$-MET PET have equivalent clinical value in the diagnostic evaluation of glioma [29, 30]. Therefore, ${ }^{18}$ F-FAMT PET imaging is likely to have similar characteristics to ${ }^{11} \mathrm{C}$-MET PET imaging for glioma diagnosis. However, the cell transport systems of ${ }^{18} \mathrm{~F}$-FAMT and ${ }^{11} \mathrm{C}-\mathrm{MET}$ may be different. L-type amino acid transporter 1 (LAT1) is a major route for the transport of large neutral amino acids, including L-tyrosine,
L-leucine, and L-methionine, through the plasma membrane. LAT1 is essential in tumor growth and is widely expressed in primary human cancers as well as gliomas [31-33]. Recent findings have proved that ${ }^{18} \mathrm{~F}$-FAMT is highly selective for LAT1 because of its $\alpha$-methyl moiety [34], which suggests that the tumor imaging sensitivity and specificity of ${ }^{18} \mathrm{~F}$-FAMT PET and ${ }^{11} \mathrm{C}$-MET PET may have subtle differences. Recently, another ${ }^{18} \mathrm{~F}$-labeled amino acid tracer, ${ }^{18} \mathrm{~F}$-FET, has been shown to be useful for PET diagnosis of glioma $[8-10,35] .{ }^{18} \mathrm{~F}$-FET $\mathrm{PET}$ has high $\mathrm{T} / \mathrm{N}$ ratio and better contrast in all gliomas compared to ${ }^{18} \mathrm{~F}$-FDG PET, similar to our findings for ${ }^{18}$ F-FAMT PET, and is a clinically valuable PET tracer for imaging of gliomas $[8-10,35] .{ }^{18}$ F-FET was clearly proved to be transported through both LAT1 and LAT2, with less selectivity for LAT1 than ${ }^{18}$ F-FAMT [34]. However, a more recent study suggested that trapping of ${ }^{18} \mathrm{~F}$-FET within the cells is caused by the asymmetry of its intra- and extracellular recognition by LAT1 [36].

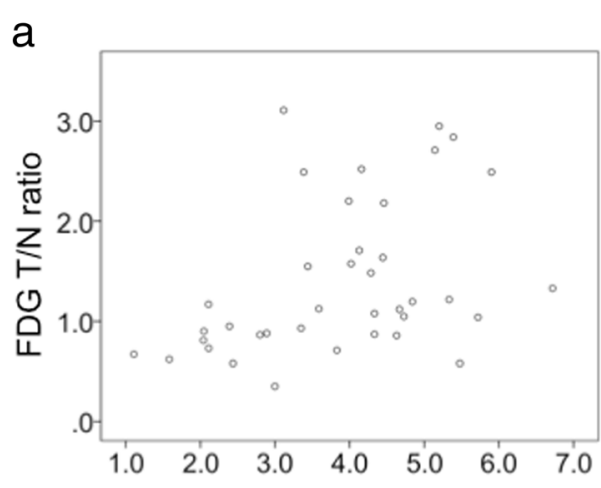

FAMT T/N ratio

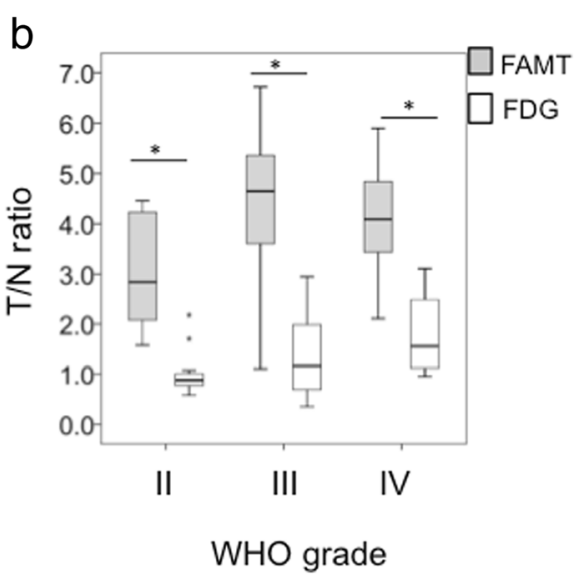

Fig. 4 a Correlation analysis between the T/N ratios of ${ }^{18} \mathrm{~F}$-FAMT PET and ${ }^{18} \mathrm{~F}$-FDG PET showed significant positive correlation in all gliomas $\left(r_{s}=0.430\right.$, $p<0.01$ ). $\mathbf{b}$ Comparison of the T/N ratios of ${ }^{18} \mathrm{~F}$-FAMT PET and ${ }^{18} \mathrm{~F}$-FDG PET found significant differences for each WHO grade (all $\left.p<0.05\right)$ 


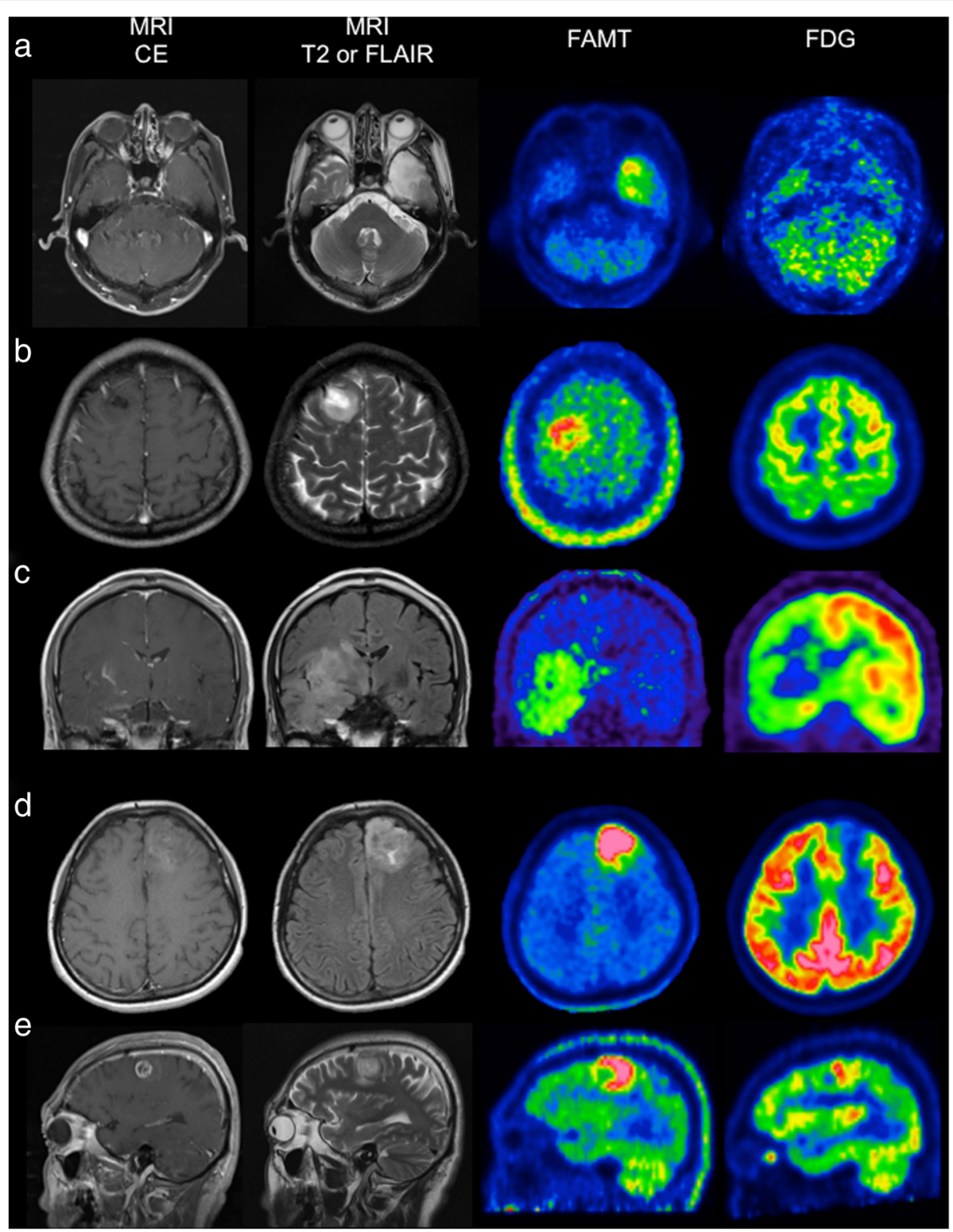

Fig. 5 Representative cases. Contrast-enhanced T1-weighted magnetic resonance images (MRI CE), T2-weighted or fluid attenuated inversion recovery images (MRI T2 or FLAIR), ${ }^{18} \mathrm{~F}$-FAMT PET images, and ${ }^{18} \mathrm{~F}$-FDG PET images, from left to right. a A 71 -year-old man with diffuse astrocytoma. ${ }^{18} \mathrm{~F}$-FAMT T/N ratio was 2.05. ${ }^{18} \mathrm{~F}$-FDG T/N ratio was 0.90. b A 32-year-old man with oligoastrocytoma. ${ }^{18} \mathrm{~F}$-FAMT T/N ratio was $2.80 .{ }^{18} \mathrm{~F}-\mathrm{FDG}$ T/N ratio was 0.86 . c A 50-year-old man with anaplastic astrocytoma. ${ }^{18} \mathrm{~F}$-FAMT T/N ratio was 5.33. ${ }^{18} \mathrm{~F}$-FDG T/N ratio was 1.22 . d A 39-year-old woman with anaplastic oligoastrocytoma. ${ }^{18} \mathrm{~F}$-FAMT T/N ratio was $5.48 .{ }^{18} \mathrm{~F}$-FDG T/N ratio was 0.58 . e A 56 -year-old man with glioblastoma. ${ }^{18} \mathrm{~F}$-FAMT T/N ratio was 4.73. ${ }^{18} \mathrm{~F}-\mathrm{FDG}$ T/N ratio was 1.05

Therefore, ${ }^{18} \mathrm{~F}$-FET and ${ }^{18} \mathrm{~F}$-FAMT have similar characteristics as ${ }^{18} \mathrm{~F}$-based brain tumor imaging tracers, but with structural differences and different biological activities. Standard ${ }^{18} \mathrm{~F}$-FET summation image analysis of the 20-40 min time frame revealed mean maximum tumor-to-background ratio $\left(\mathrm{TBR}_{\max }\right)$ of 2.1 in LGGs and significantly higher $\mathrm{TBR}_{\max }$ of 3.3 in HGGs $(p<$ 0.001) [37]. ROC analyses revealed a cutoff value of $\mathrm{TBR}_{\max } 2.7$ for the differentiation between LGGs and HGGs in the conventional 20-40 min summation images (sensitivity 66.7\%, specificity $77.9 \%$, accuracy 70.4\%) [37]. In our series, ROC analysis for differentiation between HGGs and LGGs yielded an optimal cutoff value of 3.37 for the $\mathrm{T} / \mathrm{N}$ ratio of ${ }^{18} \mathrm{~F}$-FAMT (sensitivity $81 \%$, specificity $67 \%$, accuracy $76 \%$ ) The cutoff value is higher than for ${ }^{18} \mathrm{~F}$-FET PET, but the accuracy of ${ }^{18}$ F-FAMT uptake may be considered equivalent. Further study is required for comparison of the imaging characteristics of ${ }^{18}$ F-FET PET and ${ }^{18}$ F-FAMT PET for the diagnosis of glioma. 
MIB-1 LI is considered to be an indicator of the simple cell proliferation rate. In contrast, WHO grade is a direct index of the malignancy grade, based on the consideration of various pathological factors, including the presence of necrosis, nuclear polymorphism, microvascular proliferation, mitotic activity, etc. The present investigation found that the $\mathrm{T} / \mathrm{N}$ ratio of ${ }^{18} \mathrm{~F}$ FAMT PET was not correlated, but the $\mathrm{T} / \mathrm{N}$ ratio of ${ }^{18}$ F-FDG PET was correlated with MIB-1 LI in all gliomas. The increase in ${ }^{18}$ F-FAMT uptake does not necessarily indicate high cell proliferation activity. Comparisons of the $\mathrm{T} / \mathrm{N}$ ratios of ${ }^{11} \mathrm{C}$-MET PET and the MIB-1 LI have found a significant correlation in diffuse astrocytoma but not in oligodendroglial tumor $[5,26,28]$. In our cohort, the ratio of diffuse astrocytoma was small, and the larger ratio of oligodendroglial tumor may have affected our results suggesting the $\mathrm{T} /$ $\mathrm{N}$ ratio of ${ }^{18} \mathrm{~F}$-FAMT PET was not correlated with MIB-1 LI in all gliomas.

The glucose metabolic rate is highest in the brain parenchyma compared to the other organs of the body. Consequently, ${ }^{18} \mathrm{~F}$-FDG is less effective as a tracer for the diagnostic imaging of brain tumor. Therefore, novel non- ${ }^{18}$ F-FDG brain tumor radiotracers have been intensively researched in the past decade [2]. Multiple studies have compared brain tumor imaging with radiolabeled amino acids and ${ }^{18} \mathrm{~F}$-FDG with the general finding that amino acids are more sensitive than ${ }^{18} \mathrm{~F}$ FDG to detect brain tumors [12, 38-47]. Amino acids provide higher tumor-normal brain contrast and are better suited to delineate the tumor extent, to differentiate tumor recurrence from treatment-related changes, and to assess treatment response. Whether ${ }^{18} \mathrm{~F}$-FDG or amino acids is the better choice for grading and prognosis remains controversial [48]. In our study, the $\mathrm{T} / \mathrm{N}$ ratios of ${ }^{18}$ F-FAMT PET and ${ }^{18} \mathrm{~F}$-FDG PET in the ROC analysis were almost equivalent for the differential diagnosis of tumor grade. ${ }^{18} \mathrm{~F}$-FAMT uptake in the normal brain parenchyma was 0.94 (median SUV) in our series, lower than that of ${ }^{18} \mathrm{~F}$-FDG, and almost the same as that of ${ }^{11} \mathrm{C}$-MET [27] and ${ }^{18}$ F-FET [8]. ${ }^{18}$ F-FAMT PET provided clearer imaging with higher $\mathrm{T} / \mathrm{N}$ ratio and better contrast in all gliomas compared to ${ }^{18} \mathrm{~F}$-FDG PET. Delineation of tumor extent and definition of the optimal site for biopsy are well-known and important advantages of amino acid PET at initial evaluation of brain tumors [38-40, 45]. In this study, the difference in $\mathrm{T} / \mathrm{N}$ ratio between ${ }^{18} \mathrm{~F}$-FAMT PET and ${ }^{18} \mathrm{~F}$-FDG PET was significant. We are interested in whether ${ }^{18} \mathrm{~F}$ FAMT PET can provide valuable data for the decisions concerning evaluation of true tumor size, extent of tumor excision range, and identification of the optimal site for biopsy. Further study will be necessary for these investigations.
More reliable grading may be possible with dynamic ${ }^{18} \mathrm{~F}$-FET PET, since this tracer exhibits differences in the time-activity curves of tracer uptake depending on tumor grade [34]. HGGs are characterized by an early peak around 10-15 min after injection followed by a decrease of ${ }^{18}$ F-FET uptake. In contrast, LGGs typically exhibit delayed and steadily increasing tracer uptake [49]. The differential kinetics of tracer uptake in HGGs and LGGs appear to be a special property of ${ }^{18} \mathrm{~F}$-FET because such differences were not observed with ${ }^{11} \mathrm{C}$ MET or L-6- $\left[{ }^{18} \mathrm{~F}\right]$ fluoro-3,4-dihydroxyphenylalnine [11, 50]. Therefore, dynamic study with ${ }^{18} \mathrm{~F}$-labeled tracer may be useful as an indicator of tumor grade. Further dynamic study using ${ }^{18}$ F-FAMT PET will be necessary in the future.

There were limitations to the present study. This study was based on relatively strict pathological and grading differentiations in astrocytomas and oligodendroglial tumors. Therefore, some pathological categories included a relatively small number of samples. Furthermore, simultaneous ${ }^{18} \mathrm{~F}$-FAMT PET and ${ }^{18} \mathrm{~F}$-FDG PET imaging is the ideal method of comparison. Since both tracers are labeled with fluorine, the tracer half-life requires a suitable interval between these PET studies. In these 38 cases, the interval between ${ }^{18} \mathrm{~F}$-FAMT PET and ${ }^{18} \mathrm{~F}$-FDG PET studies ranged from 1 to 38 days, and the median was 5 days. Recently, accumulation of ${ }^{18}$ F-FAMT was reported to be strongly correlated with the expression of LAT1 in cancers [34]. However, correlation of ${ }^{18} \mathrm{~F}$ FAMT transport and LAT1 expression was not examined in this study. A further study will be needed to investigate the mechanism of ${ }^{18} \mathrm{~F}$-FAMT accumulations in gliomas. ${ }^{18}$ F-FAMT is a new radiotracer for brain tumor imaging. More experience with cases of gliomas or other brain tumors is needed. A comparative study with radiotracers other than ${ }^{18} \mathrm{~F}$-FDG is also needed to clarify the diagnostic utility of ${ }^{18}$ F-FAMT PET.

\section{Conclusions}

${ }^{18} \mathrm{~F}$-FAMT is a useful radiotracer for the preoperative evaluation of tumor malignancy. ${ }^{18}$ F-FAMT PET provides clearer imaging with higher $\mathrm{T} / \mathrm{N}$ ratio and better contrast compared to ${ }^{18} \mathrm{~F}$-FDG PET in all gliomas. Therefore, ${ }^{18}$ F-FAMT is a useful radiotracer for the preoperative visualization of gliomas.

\footnotetext{
Abbreviations

AUC: Area under the curve; Cl: Confidence interval; C-MET: L-[methyl${ }^{11} \mathrm{C}$ methionine; CT: Computed tomography; F-FAMT: Fluorine-18amethyltyrosine; F-FDG: Fluorine-18 fluorodeoxyglucose; F-FET: O-(2 $\left[{ }^{18} \mathrm{~F}\right]$ fluoroethyl)-L-tyrosine; HGG: High-grade glioma; LAT1: L-type amino acid transporter 1; LGG: Low-grade glioma; MIB-1 LI: MIB-1 labeling index; NPV: Negative predictive value; PET: Positron emission tomography; PPV: Positive predictive value; ROC: Receiver operating characteristic; ROI: Region of interest; SUV: Standardized uptake value; SUV $V_{\text {max }}$ Maximum SUV; T/N ratio: Tumor to normal brain ratio; TBR max: Maximum tumor-tobackground ratio; WHO: World Health Organization
} 


\section{Acknowledgements}

We thank the following neuroradiologists for critical comments: Dr. Azusa Tokue of Department of Diagnostic Radiology and Nuclear Medicine, Gunma University Graduate School of Medicine, Maebashi, Gunma, Japan, and Dr. Takashi Shibasaki of Neurosurgery Section, Yuaikinen Hospital, Koga, Ibaraki, Japan. We also thank the following radiological technologist for technical assistance: Tsuyoshi Otake, Kazuhiro Kishi, and Hidenori Otake of Department of Diagnostic Radiology and Nuclear Medicine, Gunma University Graduate School of Medicine.

\section{Funding}

None.

\section{Authors' contributions}

$\mathrm{KH}$ is the guarantor of integrity of the entire study, is responsible for the data analysis, statistical analysis, and manuscript writing. MT contributed to the study design, literature research, and manuscript editing. TH and YA helped in the data collection and data analysis. KS carried out the clinical study and data collection. JH and $\mathrm{YH}$ helped in the data analysis. $Y T$ and $Y Y$ contributed to the manuscript review. All authors read and approved the final manuscript.

\section{Competing interests}

The authors declare that they have no competing interests.

\section{Consent for publication}

All patients agreed to participate in this study, and provided written informed consent.

\section{Ethics approval and consent to participate}

This study was approved by the institutional review board of Gunma University Graduate School of Medicine.

\section{Publisher's Note}

Springer Nature remains neutral with regard to jurisdictional claims in published maps and institutional affiliations.

\section{Author details}

'Department of Neurosurgery, Gunma University Graduate School of Medicine, 3-39-22 Showa-machi, Maebashi, Gunma 371-8511, Japan. 2Department of Diagnostic Radiology and Nuclear Medicine, Gunma University Graduate School of Medicine, Maebashi, Gunma, Japan. ${ }^{3}$ Department of Human Pathology, Gunma University Graduate School of Medicine, Maebashi, Gunma, Japan. ${ }^{4}$ Department of Pathology, Gunma University Hospital, Maebashi, Gunma, Japan.

\section{Received: 14 February 2017 Accepted: 22 May 2017}

\section{Published online: 31 May 2017}

\section{References}

1. Di Chiro G, Brooks RA. PET-FDG of untreated and treated cerebral gliomas. J Nucl Med. 1988;29:421-3.

2. Gulyás B, Halldin C. New PET radiopharmaceuticals beyond FDG for brain tumor imaging. Q I Nucl Med Mol Imaging. 2012;56:173-90.

3. Albert NL, Weller M, Suchorska B, Galldiks N, Soffietti R, Kim MM, et al. Response Assessment in Neuro-Oncology working group and European Association for Neuro-Oncology recommendations for the clinical use of PET imaging in gliomas. Neuro Oncol. 2016;18:1199-208.

4. Langen KJ, Watts C. Neuro-oncology: amino acid PET for brain tumours-ready for the clinic? Nat Rev Neurol. 2016;12:375-6.

5. Shinozaki N, Uchino Y, Yoshikawa K, Matsutani T, Hasegawa A, Saeki N, et al. Discrimination between low-grade oligodendrogliomas and diffuse astrocytoma with the aid of ${ }^{11} \mathrm{C}$-methionine positron emission tomography. J Neurosurg. 2011;114:1640-7.

6. Glaudemans AW, Enting RH, Heesters MA, Dierckx RA, van Rheenen RW, Walenkamp AM, et al. Value of ${ }^{11} \mathrm{C}$-methionine PET in imaging brain tumours and metastases. Eur J Nucl Med Mol Imaging. 2013;40:615-35.

7. Ohtani T, Kurihara H, Ishiuchi S, Saito N, Oriuchi N, Inoue T, et al. Brain tumour imaging with carbon-11 choline: comparison with FDG PET and gadolinium-enhanced MR imaging. Eur J Nucl Med. 2001;28:1664-70.
8. Weber WA, Wester HJ, Grosu AL, Herz M, Dzewas B, Feldmann HJ, et al. O(2- $\left[{ }^{18} \mathrm{~F}\right]$ fluoroethyl)-L-tyrosine and L-[methyl $\left.{ }^{11} \mathrm{C}\right]$ methionine uptake in brain tumours: initial results of a comparative study. Eur J Nucl Med. 2000;27:542-9.

9. Floeth FW, Pauleit D, Wittsack HJ, Langen KJ, Reifenberger G, Hamacher K, et al. Multimodal metabolic imaging of cerebral gliomas: positron emission tomography with $\left[{ }^{18} \mathrm{~F}\right]$ fluoroethyl-L-tyrosine and magnetic resonance spectroscopy. J Neurosurg. 2005;102:318-27.

10. Pauleit D, Floeth F, Hamacher K, Riemenschneider MJ, Reifenberger G, Müller HW, et al. O-(2-[ $\left.{ }^{18} \mathrm{~F}\right]$ fluoroethyl)-L-tyrosine PET combined with MRI improves the diagnostic assessment of cerebral gliomas. Brain. 2005;128:678-87.

11. Kratochwil C, Combs SE, Leotta K, Afshar-Oromieh A, Rieken S, Debus J, et al. Intra-individual comparison of ${ }^{18} \mathrm{~F}$-FET and ${ }^{18} \mathrm{~F}$-DOPA in PET imaging of recurrent brain tumors. Neuro Oncol. 2014;16:434-40.

12. Tripathi M, Sharma R, D'Souza M, Jaimini A, Panwar P, Varshney R, et al. Comparative evaluation of F-18 FDOPA, F-18 FDG, and F-18 FLT-PET/CT for metabolic imaging of low grade gliomas. Clin Nucl Med. 2009;34:878-83.

13. Langen KJ, Tonn JC, Weller M, Galldiks N. Letter to the Editor: "The role of imaging in the management of progressive glioblastoma. A systematic review and evidence-based clinical practice guideline" [J Neurooncol 2014;118:435-460]. J Neurooncol. 2014;120:665-6.

14. Tomiyoshi K, Amed K, Muhammad S, Higuchi T, Inoue T, Endo K, et al. Synthesis of isomers of ${ }^{18} \mathrm{~F}$-labelled amino acid radiopharmaceutical: position 2- and 3-L- ${ }^{18} \mathrm{~F}$-alpha-methyltyrosine using a separation and purification system. Nucl Med Commun. 1997;18:169-75.

15. Inoue T, Tomiyoshi K, Higuichi T, Ahmed K, Sarwar M, Aoyagi K, et al. Biodistribution studies on L-3-[fluorine-18]fluoro-alpha-methyl tyrosine: a potential tumor-detecting agent. J Nucl Med. 1998;39:663-7.

16. Kaira K, Oriuchi N, Otani Y, Shimizu K, Tanaka S, Imai H, et al. Fluorine-18-alphamethyltyrosine positron emission tomography for diagnosis and staging of lung cancer: a clinicopathologic study. Clin Cancer Res. 2007;13:6369-78.

17. Kaira K, Oriuchi N, Shimizu K, Tominaga H, Yanagitani N, Sunaga N, et al. ${ }^{18} \mathrm{~F}$-FMT uptake seen within primary cancer on PET helps predict outcome of non-small cell lung cancer. J Nucl Med. 2009;50:1770-6.

18. Kaira K, Oriuchi N, Shimizu K, Ishikita T, Higuchi T, Imai H, et al. Evaluation of thoracic tumors with (18)F-FMT and (18)F-FDG PET-CT: a clinicopathological study. Int J Cancer. 2009;124:1152-60.

19. Miyashita $G$, Higuchi $T$, Oriuchi N, Arisaka $Y$, Hanaoka $H$, Tominaga $H$, et al. ${ }^{18}$ F-FAMT uptake correlates with tumor proliferative activity in oral squamous cell carcinoma: comparative study with ${ }^{18} \mathrm{~F}$-FDG PET and immunohistochemistry. Ann Nucl Med. 2010;24:579-84.

20. Suzuki S, Kaira K, Ohshima Y, Ishioka NS, Sohda M, Yokobori T, et al. Biological significance of fluorine-18-a-methyltyrosine (FAMT) uptake on PET in patients with oesophageal cancer. Br J Cancer. 2014;110:1985-91.

21. Inoue T, Shibasaki T, Oriuchi N, Aoyagi K, Tomiyoshi K, Amano S, et al. ${ }^{18} \mathrm{~F}$ alpha-methyl tyrosine PET studies in patients with brain tumors. J Nucl Med. 1999:40:399-405.

22. Louis DN, Ohgaki H, Wiestler OD, Cavenee WK, Burger PC, Jouvet A, et al. The 2007 WHO classification of tumours of the central nervous system. Acta Neuropathol. 2007;114:97-109.

23. Inoue T, Koyama K, Oriuchi N, Alyafei S, Yuan Z, Suzuki H, et al. Detection of malignant tumors: whole-body PET with fluorine 18 alpha-methyl tyrosine versus FDG-preliminary study. Radiology. 2001;220:54-62.

24. Louis DN, Perry A, Reifenberger G, von Deimling A, Figarella-Branger D, Cavenee WK, et al. The 2016 World Health Organization Classification of Tumors of the Central Nervous System: a summary. Acta Neuropathol. 2016;131:803-20.

25. Kaschten B, Stevenaert A, Sadzot B, Deprez M, Degueldre C, Del Fiore G, et al. Preoperative evaluation of 54 gliomas by PET with fluorine-18fluorodeoxyglucose and/or carbon-11-methionine. J Nucl Med. 1998;39:778-85.

26. Kato T, Shinoda J, Oka N, Miwa K, Nakayama N, Yano H, et al. Analysis of ${ }^{11} \mathrm{C}$-methionine uptake in low-grade gliomas and correlation with proliferative activity. AJNR Am J Neuroradiol. 2008;29:1867-71.

27. Kato T, Shinoda J, Nakayama N, Miwa K, Okumura A, Yano H, et al. Metabolic assessment of gliomas using ${ }^{11} \mathrm{C}$-methionine, $\left[{ }^{18} \mathrm{~F}\right]$ fluorodeoxyglucose, and ${ }^{11} \mathrm{C}$-choline positron-emission tomography. AJNR Am J Neuroradiol. 2008;29:1176-82.

28. Derlon JM, Petit-Taboué MC, Chapon F, Beaudouin V, Noël MH, Creveuil C, et al. The in vivo metabolic pattern of low-grade brain gliomas: a positron emission tomographic study using ${ }^{18} \mathrm{~F}$-fluorodeoxyglucose and ${ }^{11} \mathrm{C}-\mathrm{L}$ methylmethionine. Neurosurgery. 1997;40:276-87. discussion 287-8. 
29. Langen KJ, Mühlensiepen $H$, Holschbach M, Hautzel $H$, Jansen $P$, Coenen $\mathrm{HH}$. Transport mechanisms of 3-[ $\left.{ }^{123} \mid\right]$ iodo-alpha-methyl-L-tyrosine in a human glioma cell line: comparison with $\left[{ }^{3} \mathrm{H}\right]$ methyl]-L-methionine. J Nucl Med. 2000:41:1250-5.

30. Langen KJ, Ziemons K, Kiwit JC, Herzog H, Kuwert T, Bock WJ, et al. 3$\left[{ }^{123} \mid\right]$ iodo-alpha-methyltyrosine and [methyl- $\left.{ }^{11} \mathrm{C}\right]-\mathrm{L}$-methionine uptake in cerebral gliomas: a comparative study using SPECT and PET. J Nucl Med. 1997;38:517-22

31. Kobayashi K, Ohnishi A, Promsuk J, Shimizu S, Kanai Y, Shiokawa Y, et al. Enhanced tumor growth elicited by L-type amino acid transporter 1 in human malignant glioma cells. Neurosurgery. 2008;62:493-503. discussion 503-4

32. Kaira K, Oriuchi N, Imai H, Shimizu K, Yanagitani N, Sunaga N, et al. L-type amino acid transporter 1 and CD98 expression in primary and metastatic sites of human neoplasms. Cancer Sci. 2008;99:2380-6.

33. Okubo S, Zhen HN, Kawai N, Nishiyama Y, Haba R, Tamiya T. Correlation of L-methyl- ${ }^{11} \mathrm{C}$-methionine (MET) uptake with L-type amino acid transporter 1 in human gliomas. J Neurooncol. 2010;99:217-25.

34. Wiriyasermkul $P$, Nagamori $S$, Tominaga $H$, Oriuchi $N$, Kaira K, Nakao H, et al. Transport of 3-fluoro-L-a-methyl-tyrosine by tumor-upregulated L-type amino acid transporter 1: a cause of the tumor uptake in PET. J Nucl Med. 2012;53:1253-61.

35. Weckesser M, Langen KJ, Rickert CH, Kloska S, Straeter R, Hamacher K, et al. $\mathrm{O}-\left(2-\left[{ }^{18} \mathrm{~F}\right]\right.$ fluorethyl)-L-tyrosine PET in the clinical evaluation of primary brain tumours. Eur J Nucl Med Mol Imaging. 2005;32:422-9.

36. Habermeier A, Graf J, Sandhofer BF, Boissel JP, Roesch F, Closs El. System L amino acid transporter LAT1 accumulates O-(2-fluoroethyl)-L-tyrosine (FET). Amino Acids. 2015:47:335-44.

37. Albert NL, Winkelmann I, Suchorska B, Wenter V, Schmid-Tannwald C, Mille E, et al. Early static (18)F-FET-PET scans have a higher accuracy for glioma grading than the standard 20-40 min scans. Eur J Nucl Med Mol Imaging. 2016:43:1105-14.

38. Goldman S, Levivier M, Pirotte B, Brucher JM, Wikler D, Damhaut P, et al. Regional methionine and glucose uptake in high-grade gliomas: a comparative study on PET-guided stereotactic biopsy. J Nucl Med. 1997;38:1459-62.

39. Pirotte B, Goldman S, David P, Wikler D, Damhaut P, Vandesteene A, et al. Stereotactic brain biopsy guided by positron emission tomography (PET) with [F-18]fluorodeoxyglucose and [C-11]methionine. Acta Neurochir Suppl. 1997:68:133-8.

40. Pirotte B, Goldman S, Massager N, David P, Wikler D, Lipszyc M, et al. Combined use of ${ }^{18} \mathrm{~F}$-fluorodeoxyglucose and ${ }^{11} \mathrm{C}$-methionine in 45 positron emission tomography-guided stereotactic brain biopsies. J Neurosurg. 2004;101:476-83.

41. Spaeth N, Wyss MT, Weber B, Scheidegger S, Lutz A, Verwey J, et al. Uptake of ${ }^{18} \mathrm{~F}$-fluorocholine, ${ }^{18} \mathrm{~F}$-fluoroethyl-L-tyrosine, and ${ }^{18} \mathrm{~F}$-FDG in acute cerebral radiation injury in the rat: implications for separation of radiation necrosis from tumor recurrence. J Nucl Med. 2004;45:1931-8.

42. Van Laere K, Ceyssens S, Van Calenbergh F, de Groot T, Menten J, Flamen P, et al. Direct comparison of ${ }^{18} \mathrm{~F}-\mathrm{FDG}$ and ${ }^{11} \mathrm{C}$-methionine PET in suspected recurrence of glioma: sensitivity, inter-observer variability and prognostic value. Eur J Nucl Med Mol Imaging. 2005;32:39-51.

43. Pauleit D, Stoffels G, Bachofner A, Floeth FW, Sabel M, Herzog H, et al. Comparison of (18)F-FET and (18)F-FDG PET in brain tumors. Nucl Med Biol. 2009;36:779-87.

44. Lau EW, Drummond K, Ware RE, Drummond E, Hogg A, Ryan G, et al. Comparative PET study using F-18 FET and F-18 FDG for the evaluation of patients with suspected brain tumour. J Clin Neurosci. 2010;17:43-9.

45. Plotkin M, Blechschmidt C, Auf G, Nyuyki F, Geworski L, Denecke T, et al. Comparison of F-18 FET-PET with F-18 FDG-PET for biopsy planning of non-contrast-enhancing gliomas. Euro Radiol. 2010;20:2496-502.

46. Miyake K, Shinomiya A, Okada M, Hatakeyama T, Kawai N, Tamiya T. Usefulness of FDG, MET and FLT-PET studies for the management of human gliomas. J Biomed Biotechnol. 2012;2012:205818.

47. Tripathi M, Sharma R, Varshney R, Jaimini A, Jain J, Souza MM, et al. Comparison of F-18 FDG and C-11 methionine PET/CT for the evaluation of recurrent primary brain tumors. Clin Nucl Med. 2012;37:158-63.

48. Galldiks N, Langen KJ. Applications of PET imaging of neurological tumors with radiolabeled amino acids. Q J Nucl Med Mol Imaging. 2015:59:70-82.
49. Calcagni ML, Galli G, Giordano A, Taralli S, Anile C, Niesen A, et al. Dynamic $\mathrm{O}-\left(2-\left[{ }^{18} \mathrm{~F}\right]\right.$ fluoroethyl)-L-tyrosine (F-18 FET) PET for glioma grading: assessment of individual probability of malignancy. Clin Nucl Med. 2011;36:841-7.

50. Moulin-Romsee G, D'Hondt E, de Groot T, Goffin J, Sciot R, Mortelmans L, et al. Non-invasive grading of brain tumours using dynamic amino acid PET imaging: does it work for ${ }^{11} \mathrm{C}$-methionine? Eur J Nucl Med Mol Imaging. 2007:34:2082-7.

\section{Submit your manuscript to a SpringerOpen ${ }^{\circ}$ journal and benefit from:}

- Convenient online submission

- Rigorous peer review

- Open access: articles freely available online

- High visibility within the field

- Retaining the copyright to your article

Submit your next manuscript at springeropen.com 